\title{
CLINICAL MEMORANDA.
}

\section{RESPIRATORY PARALYSIS IN POLIOMYELI'TIS.}

In the published accounts of poliomyelitis epidemics, comparatively little attention has been focussed on the part played by the mechanical respirator in the treatment of respiratory paralysis. Our experience of it in Shieldhall Fever Hospital may therefore be of interest.

Of 36 cases of poliomyelitis received in Shieldhall Hospital between 11th August and 10th October, 1947, of which 24 showed paralysis, four patients required treatment in the respirator. The type in use here was the Both modification of the Drinker apparatus, with which the staff was already familiar.

\section{CASE SUMMARIES.}

CASE 1. J. M., male, 6 years, admitted 27th August, on 7th day of illness. Gravely ill, semiconscious, face grey, respirations shallow and varying between 30 and 80 per minute. Pulse 146 , temp. $10: 2^{\circ}$. Left facial paralysis : unable to swallow. Nuchal rigidity and Kernig + ve. Cerebrospinal fluid at increased pressure. Cells 30, Pandy +ve. Put into respirator and given penicillin 50,000 units four-hourly.

30th August: very much better, temperature and pulse-rate normal, lip movements indicating attempts at speech. Still cannot swallow. 31st August: further improvement. Able to utter sounds. Later in day could ask for a drink. 1st September: removed from respirator. Breathing normally and able to swallow. 10th September : going on well, but face still distorted. 20th September : dismissed. 1st November: reported back. Facial paralysis shows only slight improvement.

CASE 2. G. B., male, 5 years, admitted 8 th September, on 7 th day of illness. On admission appeared moribund. Colour grey; throat full of mucus and saliva ; unable to swallow; right facial paralysis. Respiratory movements very feeble. Temp. $100^{\circ}$, pulse 164 , resp. 24 . Nuchal rigidity and Kernig + ve. Placed at once in respirator and given penicillin.

11th September: great improvement; temperature settling. 12th September: removed from respirator; breathing normally, but still unable to swallow; temperature normal. 14th September : paralysis of pharynx and of face still marked. Otherwise well. 20th September: able to swallow. 15th October: allowed up. 24th October: facial paralysis much better. Dismissed.

CASE 3. M. M., female $3 \frac{4}{12}$ years. Admitted 31st August, on 4th day of illness, as a case of laryngeal diphtheria. Condition very poor. Marked pharyngeal paralysis, with throat full of mucus, and no evidence of diphtheria. Temp. $99^{\circ}$, pulse 128 , resp. 48. No nuchal rigidity ; Kernig + ve. Clear fluid at low pressure, Pandy--ve., cells 50 . 
7th September: remains very ill; pale and limp; unable to swallow. 15th September: condition deteriorating. Respirations shallow, with little movement of chest wall. Placed in respirator. 19th September: great improvement. Able to be taken from respirator at intervals. 21st September : no further respirator treatment required. Able to swallow. Left facial paralysis now obvious. Probably of earlier onset but overlooked on account of grave general condition. 26th September: able to sit up and taking food well. 30th November: facial paralysis still very marked, otherwise well.

CASE 4. W. F., male, 23 years, admitted 12 th September, on 3rd day of illness. Gravely ill, unable to speak or move. Marked dyspnoea. Temp. $100^{\circ}$, pulse 150 , resp. 22. Intercostals not acting, but some action of diaphragm. Able to swallow. Paralysis of upper and lower limbs and paresis of abdominal and back muscles. Nuchal rigidity + ve. Put at once into respirator. Later became restless and cyanosed, but fully conscious and able to speak.

12th September: temp. 104.8, pulse 128, less restless. Rapid deterioration with increase of cyanosis. 14th September: died 7.30 a.m.

\section{COMMEN'T.}

The similarity in several respects of Cases 1,2 , and 3 will be noticed. All were young children showing a combination of facial, pharyngeal and respiratory paralysis and without paralysis of the limbs. In two of them respiratory embarrassment was evident on admission while in the third it began to declare itself some days after admission. In each the respirator brought about rapid and dramatic improvement, so that within four to six days the child could be removed from it safely.

Recovery of the pharyngeal muscles followed quickly on that of respiration, two patients being able to swallow within 24 hours of release from the respirator, and the third within a week. The facial muscles, on the other hand, were slow to recover, and still showed marked paralysis in Cases 1 and 3, eight and fifteen weeks respectively after admission ; while in Case 2 slight asymmetry of the face was evident six weeks from the onset.

There being involvement of the 7 th and 9 th cranial nerves in addition to respiratory distress, it may be assumed that each of these patients suffered from a purely bulbar lesion. The fourth case was of an entirely different type, with paralysis spreading rapidly upwards from the lower limbs, i.e., the Landry type of paralysis, and with no evidence of bulbar involvement before the terminal stage. The patient remained fully conscious, so that respiratory distress, with cyanosis and use of the accessory muscles was much more evident than in the others. Treatment in the respirator brought about no improvement, and death ensued within 48 hours of admission, no doubt from spread to the bulb and damage to both cardiac and respiratory centres.

Our experience does not altogether correspond with that of MacNalty (1938), who stated that the practical value of the respirator appeared to 
be limited to cases with temporary peripheral paralysis of the intercostal muscles and diaphragm, and that for respiratory failure of bulbar origin the apparatus.was found to be useless. Again, in a Melbourne epidemic, Scholes (1938) found that in patients treated in respirators, pharyngeal paralysis was the commonest cause of death. Fischer and Stillerman (1937), used the Drinker apparatus for eighteen patients during the New York epidemic of 1935 ; of these eight were non-bulbar in origin and six survived, while ten were bulbar as well as thoracic in type and only two recovered.

It appears clear to us that the respirator may be a life-saving measure even in the presence of a bulbar lesion that includes pharyngeal-paralysis. No record is yet available of the total number of patients who owe their recovery to its use, but it must be considerable.

REFERENCES.

Fischer, A. E. \& Stillerman, M. (1937). Amer. J. Dis. Child. 54: 984.

MacNalty, Sir A. (1938). Lancet. $1: 1288$.

Scholes, F. V. (1938) Med. J. Aust. 1: 402. Cited in Public Health section, Lancet. (1938). $1: 1080$.

SHIELDHALl, FEVER HOSPITAI, GI,AsGow.
WILLIAM NAPIER, M.D., RU'TH KEYMER, M.B. ch.B. 